\title{
Postprandial triglyceride response in Type 1 (insulin-dependent) diabetes mellitus is not altered by short-term deterioration in glycaemic control or level of postprandial insulin replacement
}

\author{
G.F.Lewis ${ }^{1}$, N.M. O'Meara' ${ }^{1}$, V.G.Cabana ${ }^{2}$, J.D. Blackman ${ }^{1}$, W. L.Pugh ${ }^{1}$, A. F. Druetzler ${ }^{1}$, J.R. Lukens ${ }^{2}$, G.S. Getz ${ }^{2}$ \\ and K.S.Polonsky ${ }^{1}$
}

The Departments of ${ }^{1}$ Medicine and ${ }^{2}$ Pathology, University of Chicago, Pritzker School of Medicine, Chicago, Illinois, USA

\begin{abstract}
Summary. The effect of deteriorating glycaemic control on the lipoprotein responses to the ingestion of a high fat meal was investigated in seven normolipidaemic Type 1 (insulindependent) diabetic patients and the results were compared with corresponding responses in seven normolipidaemic control subjects. In addition, the importance of insulin in regulating the postprandial lipoprotein responses was examined by comparing the results obtained from the diabetic patients maintained on a basal infusion of insulin throughout the study with those obtained when a step-up, step-down insulin infusion was administered following the meal. Vitamin A was added to the test meal in all subjects to trace the metabolism of the chylomicron $\left(\mathrm{S}_{\mathrm{f}}>1000\right)$ and non-chylomicron $\left(S_{\mathrm{p}}<1000\right)$ fractions in the postprandial period. No differences in fasting and postprandial triglyceride levels nor in the concentration of the chylomicron and non-chylomicron fractions were observed between diabetic and control
\end{abstract}

subjects. In the diabetic patients short-term (two-week) deterioration in glycaemic control did not have any adverse influence on the basal and postprandial lipid responses. However, while the amount of insulin administered after the meal in the diabetic patients did not have any effect on the postprandial triglyceride or chylomicron responses, the concentration of non-esterified fatty acids was significantly higher $(p<0.0005)$ when only a basal infusion of insulin was administered. In conclusion: 1) Short-term deterioration in glycaemic control does not adversely affect lipoprotein concentrations in Type 1 diabetes. 2) Non-esterified fatty acids appear to be a more sensitive index of insulinization postprandially than triglycerides.

Key words: Postprandial, triglyceride, retinyl, Type 1 (insulin-dependent) diabetes mellitus, fatty acid.
Poor glycaemic control in patients with Type 1 (insulindependent) diabetes mellitus is associated with abnormalities in fasting lipids, most frequently hypertriglyceridaemia [1-4]. A number of studies have demonstrated improvements in the abnormal lipoprotein profile when patients who are in poor metabolic control are placed on more aggressive regimens of insulin replacement which result in improvements in the plasma glucose concentrations [5-9]. These effects are related to the fact that insulin plays a key role in the regulation of very low density lipoprotein (VLDL) production by the liver [10] and is also an important regulator of lipoprotein lipase [11], the ratelimiting enzyme in the catabolism of both VLDL and enteric chylomicrons.

Patients with Type 1 diabetes frequently experience short-term variations in metabolic control with elevations in the plasma glucose concentration, particularly in the postprandial state. The effect of these alterations in glucose control on the lipid and lipoprotein profiles both in the fasting state and postprandially is not known. In the present study, we have prospectively reduced the insulin dose over a two-week period in Type 1 diabetic patients previously in good metabolic control and measured the effect on plasma lipids. The effect of variations in the acute replacement dose of insulin at the time of the meal ingestion was also studied. The rationale behind this study design was to simulate the short-term variations in glucose control which frequently occur in the everyday lives of patients with Type 1 diabetes.

\section{Subjects and methods}

Studies were performed on seven patients with Type 1 diabetes who were free of complications and otherwise in good health and seven non-diabetic control subjects well matched for age $(30.3 \pm 2.0$ years vs $30.0 \pm 2.2$ years, mean \pm SEM: range $21-40$ years $)$, sex ( 6 females and 1 male in each group) and BMI $\left(23.9 \pm 0.8 \mathrm{~kg} / \mathrm{m}^{2}\right.$ vs $23.8 \pm 0.9 \mathrm{~kg} / \mathrm{m}^{2}$ : range 20.5 to $27.1 \mathrm{~kg} / \mathrm{m}^{2}$ ). All subjects were normolipidaemic as defined by fasting plasma triglycerides $<150 \mathrm{mg} / \mathrm{dl}$, total cholesterol $<90$ th percentile and HDL cholesterol $>5$ th per- 
centile for the U.S. population for age and sex (12). Other than insulin, no subject was taking any medication known to affect lipid metabolism (i.e., oral contraceptives, thiazide diuretics, Beta blockers, lipid-lowering agents) and all had stable body weight for at least one month prior to the study. The duration of diabetes in the seven diabetic patients was $16.3 \pm 0.8$ years (range 13 to 19 years) and $\mathrm{HbA}_{\mathrm{l}}$ concentration $9.9 \pm 0.4 \%$ (range 8.8 to $11.7 \%$ ), the mean $\mathrm{HbA}_{1 \mathrm{C}}$ for the non-diabetic population in this laboratory being $5.16 \pm 0.06 \%$. Six of the diabetic subjects were treated with a conventional insulin regimen consisting of NPH and regular human insulin and the remaining patient was treated with the continuous subcutaneous insulin infusion (CSII) pump. Individualized weightmaintaining diabetic diet patterns were designed for each control subject and dietary patterns were followed for two weeks prior to receiving the high fat test meal. Subjects gave written informed consent and the protocol was approved by the Institutional Review Board.

\section{Study design}

Type 1 diabetic patients were studied on three occasions each, two weeks apart and control subjects were studied on a single occasion only. On each occasion subjects received the identical lipid-rich test meal. The study was designed to examine:

1. The effect of variations in plasma glucose control during the preceding two-week period on fasting and postprandial lipid and lipoprotein responses.

2. The effect of variations in the dose of insulin administered immediately following the meal on the metabolism of triglyceride-rich particles in the postprandial period.

3. The differences in postprandial lipoprotein metabolism between Type 1 diabetic patients in moderate glycaemic control and nondiabetic matched control subjects.

To address these issues, the three studies involving Type 1 diabetic patients were designed as follows:

1. Poor control/basal infusion: For this study, the daily insulin dose for the two weeks preceding the test meal was decreased by approximately one third, in order to raise the mean pre-meal glucose to the 14-17 mmol/1 range. Subjects monitored urine for ketones daily and none developed ketonuria. After two weeks, following a $14 \mathrm{~h}$ overnight fast, subjects were admitted to the Clinical Research Centre (CRC) having administered their last subcutaneous insulin dose $14 \mathrm{~h}$ previously or, in the case of the patient being treated with CSII, the normal nocturnal basal insulin infusion was continued overnight (rate $1.3 \mathrm{U} / \mathrm{h}$ ). The mean insulin dose administered on the evening prior to the study to the six patients receiving conventional insulin therapy was $18 \pm 2 \mathrm{U}$. Following admission, an intravenous catheter was placed in each forearm, one for blood sampling and one for insulin infusion. The arm containing the sampling catheter was maintained in a heating blanket to ensure arterialization of the venous sample and physiological $\mathrm{NaCl}(0.15 \mathrm{~mol} / \mathrm{l})$ was infused through this catheter to maintain patency. Thirty minutes prior to the test meal, a low basal infusion of insulin (Eli Lilly Co., Indianapolis, Ind., USA) was started in the other arm at $0.4 \mathrm{U} / \mathrm{h}$ and continued throughout the $24 \mathrm{~h}$ study period.

2. Good control/basal infusion: In this study, subjects were placed in good metabolic control during the preceding two weeks but the insulin dose was maintained at basal levels following ingestion of the test meal. Subjects were admitted to the CRC on the evening prior to being studied. An intravenous infusion of regular human insulin was started in a forearm vein and blood glucose was held constant in the $5-6 \mathrm{mmol} / 1$ range according to the method described by White et al.
[13]. Using this approach, the mean insulin infusion rate required to maintain euglycaemia overnight was $1.1+0.2 \mathrm{U} / \mathrm{h}$. After fasting overnight for $14 \mathrm{~h}$, a second intravenous sampling catheter was inserted into the opposite forearm. Thirty minutes prior to meal ingestion, the insulin infusion rate was changed to $0.4 \mathrm{U} / \mathrm{h}$ and maintained constant at this rate for the duration of the $24 \mathrm{~h}$ study.

3. Good control/step-up infusion: This was identical to the good control/basal infusion study with the exception that at the start of the test meal, the insulin infusion was increased incrementally so that the peak postprandial glucose level did not rise above $10.0 \mathrm{mmol} / 1$. The rate was then slowly decreased and after 6 to $8 \mathrm{~h}$, the glucose level was held constant at $5-6 \mathrm{mmol} / \mathrm{l}$ by a variable rate insulin infusion. During the $24 \mathrm{~h}$ following the meal the mean insulin dose administered to the diabetic patients was $36.9 \pm 2.8 \mathrm{U}$ with $45.4 \pm 3.8 \%$ of the total dose being administered in the first $4 \mathrm{~h}$ as the insulin dose was being incrementally increased in an attempt to simulate the normal insulin and glucose responses observed in the peripheral circulation in the postprandial period. This approach will not however reproduce the high portal venous insulin concentrations normally attained in the postprandial period in non-diabetic subjects, levels which are not seen in the peripheral circulation due to the large hepatic extraction of insulin.

The order of the three diabetic studies was randomized using a table of random numbers. Glycaemic control during each preceding twoweek period was monitored by subjects at home using a portable reflectance meter.

The non-diabetic control subjects were admitted to the $\mathrm{CRC}$ on the morning of the test meal following a 14 h overnight fast. They did not receive an insulin infusion and a single sampling intravenous catheter was placed in a forearm vein. The test meal and sampling was identical to that described for the diabetic subjects (see below).

The detailed composition of the test meal which contained $60 \mathrm{~g}$ fat $/ \mathrm{m}^{2}$ body surface area has been previously described (14). To trace the metabolism of chylomicrons and chylomicron remnants in the postprandial period, Vitamin A (Aquasol A; 5,000 U/0.1 ml; Armour Pharmaceutical Co., Kankakee, Ill., USA) was added to half a cup of milk and ingested at the start of the meal. Each subject received $60,000 \mathrm{U}$ Vitamin $\mathrm{A} / \mathrm{m}^{2}$ body surface area. Vitamin $\mathrm{A}$ when ingested with fat is absorbed predominantly as retinyl palmitate (RP), packaged within the chylomicron core. RP is not exchanged with core lipids of higher density lipoprotein particles to any significant extent in the early postprandial period and remains an integral part of the chylomicron remnant particle after hydrolysis of chylomicrons by lipoprotein lipase, finally being taken up with the remnants by the liver where it is not resecreted with VLDL [15-19]. The measurement of RP levels in serum postprandially therefore can be used to study in isolation, the metabolism of exogenous (dietary) triglyceride-rich particles, an approach which is not possible through the measurement of serum triglyceride levels alone. In these studies we measured RP levels in whole serum and in serum which had been fractionated into large chylomicron (Svedberg flotation units $\left.\left(S_{\mathrm{f}}\right)>1000\right)$ and small non-chylomicron $\left(\mathrm{S}_{\mathrm{f}}<1000\right)$ fractions as previously described $[15,20]$, the non-chylomicron fraction consisting mainly of RP-labelled chylomicron remnants.

Having consumed the test meal, all subjects did not eat again for $24 \mathrm{~h}$ but were allowed free access to water after $8 \mathrm{~h}$. Blood samples for glucose, insulin, C-peptide and lipid parameters were drawn before the meal and every hour after the meal up to $6 \mathrm{~h}$, then every $2 \mathrm{~h}$ up to $14 \mathrm{~h}$ and at $24 \mathrm{~h}$.

\section{Chemical determinations}

The methods used for the separation of the lipoprotein fractions and for analysis of the various lipids in each fraction have previously been described [14]. Non-esterified fatty acids were determined using the colorimetric chemical method described by Mikac-Devic [21]. Protein content of the lipoproteins was quantitated by a modi- 
Table 1. Indices of two-week glycaemic control and fasting lipid parameters prior to each test meal

\begin{tabular}{|c|c|c|c|c|}
\hline & $\begin{array}{l}\text { Type } 1 \text { diabetic subjects } \\
\text { Good control/ } \\
\text { basal infusion }\end{array}$ & $\begin{array}{l}\text { Type } 1 \text { diabetic subjects } \\
\text { Good control/ } \\
\text { step-up infusion }\end{array}$ & $\begin{array}{l}\text { Type } 1 \text { diabetic subjects } \\
\text { Poor control/ } \\
\text { basal infusion }\end{array}$ & $\begin{array}{l}\text { Control } \\
\text { subjects }\end{array}$ \\
\hline $\begin{array}{l}\text { Triglycerides } \\
(\mathrm{mmol} / \mathrm{l})\end{array}$ & $0.72 \pm 0.05$ & $0.75 \pm 0.04$ & $0.68 \pm 0.08$ & $0.82 \pm 0.07$ \\
\hline $\begin{array}{l}\text { HDL-cholesterol } \\
(\mathrm{mmol} / \mathrm{l})\end{array}$ & $1.13 \pm 0.07$ & $1.14 \pm 0.07$ & $1.26 \pm 0.08$ & $1.13 \pm 0.05$ \\
\hline $\begin{array}{l}\text { Non-esterified fatty acids } \\
(\mathrm{mmol} / \mathrm{l})\end{array}$ & $0.562 \pm 0.120$ & $0.677 \pm 0.127$ & $0.861 \pm 0.048$ & $0.791 \pm 0.063$ \\
\hline $\begin{array}{l}\text { Pre-meal blood glucose average over } 2 \text { weeks } \\
(\mathrm{mmol} / \mathrm{l})\end{array}$ & $7.78 \pm 0.33$ & $7.48 \pm 0.46$ & $13.19 \pm 0.69^{a}$ & \\
\hline $\begin{array}{l}\text { Daily insulin dose average over } 2 \text { weeks } \\
\text { (units/day) }\end{array}$ & $58.6 \pm 5.9$ & $58.6 \pm 5.9$ & $40.7 \pm 4.4^{\mathrm{a}}$ & \\
\hline
\end{tabular}

Results are expressed as mean \pm SEM. ${ }^{a} p=0.0001$

fied Lowry procedure [22] with sodium dodecyl sulphate to disrupt the lipid micelles. Plasma for retinyl ester determination, having been collected in aluminium foil-covered tubes to minimize light exposure was separated immediately by centrifugation $(3,000 \mathrm{rev} / \mathrm{min})$ for $10 \mathrm{~min}$ at $4{ }^{\circ} \mathrm{C}$ and then subjected to preparative ultracentrifugation for $21 \mathrm{~min}$ at $25,000 \mathrm{rev} / \mathrm{min}$ in a Beckman SW55TI rotor to float chylomicron particles of $S_{\mathrm{f}}>1,000$. Aliquots of whole plasma, $\mathrm{S}_{\mathrm{f}}>1,000$ fraction and $\mathrm{S}_{\mathrm{f}}<1,000$ fraction were stored at $-70^{\circ} \mathrm{C}$ and assayed later for retinyl ester using a modification [14] of the method of De Ruyter and De Leenheer [23].

Glucose measurement and radioimmunoassays of insulin and C-peptide. Serum insulin [24] and plasma C-peptide [25] were measured as previously described. Since two of the diabetic patients had detectable levels of insulin antibodies in their serum, insulin concentrations were only measured in five of the seven diabetic patients studied. Plasma glucose was measured by glucose analyser (YSI model $23 \mathrm{~A}$, Yellow Springs, Ohio, USA).

\section{Statistical analysis}

All results are expressed as the mean \pm SEM. The absolute and incremental areas under the respective response curves were calculated as summary measures by the trapezoidal rule. To test for differences in response to the three protocols in Type 1 diabetes, a repeated measures ANOVA was performed with a Tukey allowance for multiple comparisons ( $p<0.05$ was regarded as statistically significant). To test for differences between the non-diabetic control and diabetic subjects, the responses under the good control/step-up infusion protocol were compared to those in control subjects by the two sample $t$-test. (This was the primary comparison of interest because the insulin increment in the diabetic subjects mimicked the non-diabetic response as closely as possible; $p<0.05$ was regarded as statistically significant). We also compared the two other diabetic protocols with the normal control subjects and here a $p$-value of $<0.025$ was regarded as statistically significant to allow for multiple testing. For relevant comparisons the $95 \%$ confidence intervals are also reported. Throughout the manuscript, the $p$-value for testing the overall hypothesis of equal means is reported while the significance of differences in the post hoc tests were conducted at the $5 \%$ level. Pearson correlation coefficients between all measured variables and areas under the postprandial concentration curves were calculated.

Data analysis was performed using the Statistical Analysis System (SAS Version 6 for Personal Computers, SAS Institute, Cary, NC, USA).

\section{Results}

\section{Preprandial lipid and glucose levels (Table 1)}

The mean pre-meal blood glucose levels and daily insulin dose for diabetic subjects for the two weeks prior to each test meal in addition to the fasting lipid levels on the morning of each study are listed in Table 1. On average, in the poor control/basal infusion study, the daily insulin dose was decreased by approximately one third and this resulted in an increase in the mean daily plasma glucose level from approximately $7.5 \mathrm{mmol} / \mathrm{l}$ to $13 \mathrm{mmol} / \mathrm{l}$. Mean pre-meal blood glucose measurements during the twoweek period were significantly greater in the poor vs the good control period $(p=0.0001)$. However, despite the increase in the plasma glucose, fasting lipid parameters did not differ significantly between any of the three protocols in the diabetic patients or between diabetic and control subjects. The $95 \%$ confidence interval for differences between the fasting triglycerides of the poor control/basal infusion protocol and the good control/basal infusion protocol was -0.20 to $0.12 \mathrm{mmol} / \mathrm{l}$ and between the poor control/basal infusion protocol and the good control/stepup infusion protocol was -0.23 to $0.09 \mathrm{mmol} / \mathrm{l}$.

\section{Postprandial glucose and insulin concentrations (Fig. 1)}

Following the overnight euglycaemic insulin infusion, the fasting glucose for the good control/basal infusion protocol was similar to the good control/step-up infusion protocol $(5.4 \pm 0.2 \mathrm{mmol} / \mathrm{l}$ vs $5.7 \pm 0.2 \mathrm{mmol} / \mathrm{l})$ and only the latter was slightly higher than the fasting glucose concentration in the control subjects $(5.0 \pm 0.2 \mathrm{mmol} / 1, p<0.05)$. When maintained in poor glycaemic control for two weeks, the diabetic patients had significantly higher blood glucose concentrations on the morning of the test meal $(15.5 \pm 1.2 \mathrm{mmol} / \mathrm{l}, p=0.0001)$.

Following ingestion of the test meal in the good control/basal infusion study, the glucose rose to a maximum of $20.2 \pm 0.6 \mathrm{mmol} / \mathrm{l}$ at $5 \mathrm{~h}$ and decreased slowly to 

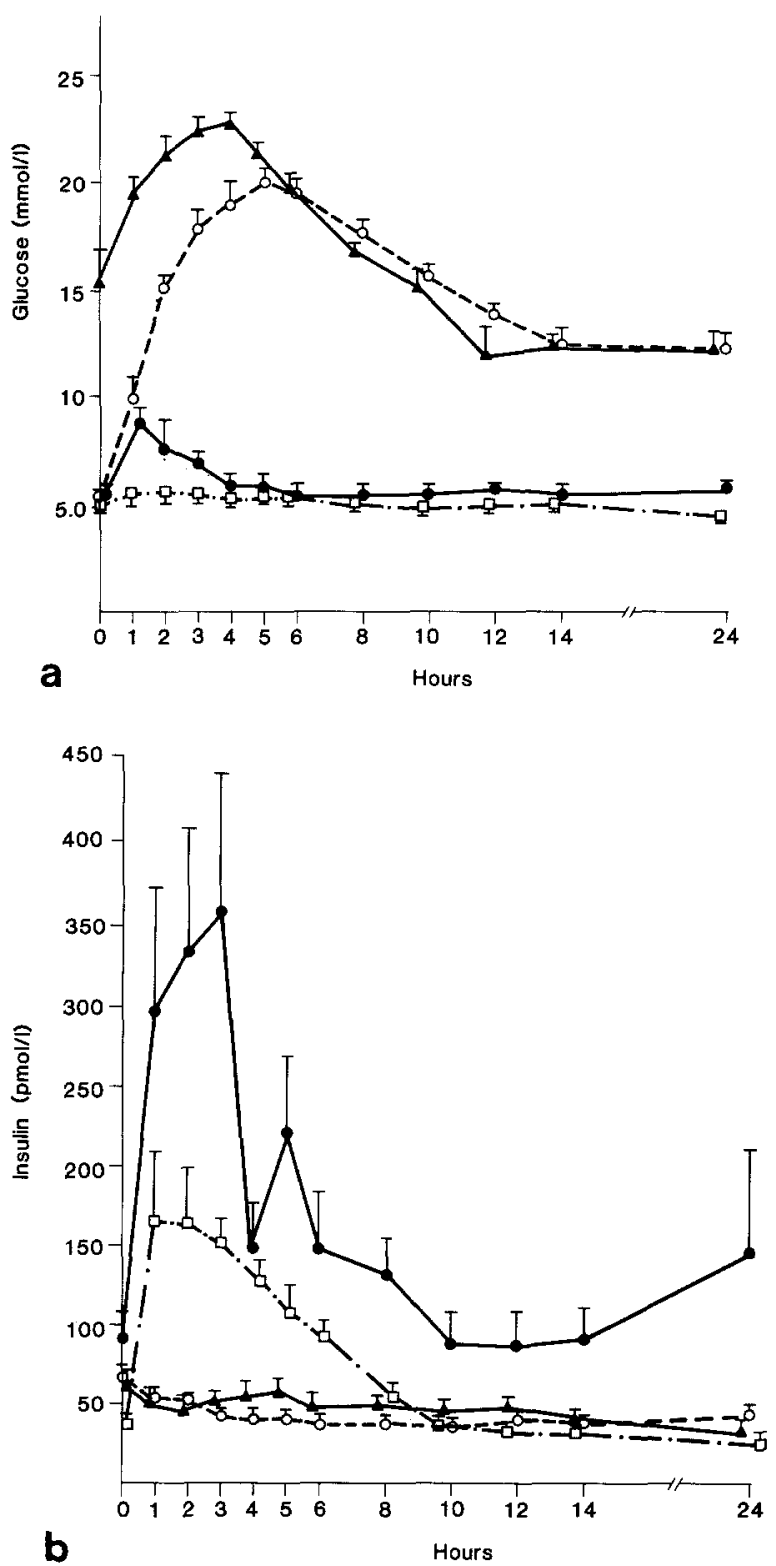

Fig. 1. Glucose and insulin concentrations at baseline (zero hour) and for $24 \mathrm{~h}$ following ingestion of the test meal for control subjects ( $\square---\square$ ) and diabetic patients studied in the three protocols: Good control/basal infusion (०---), good control/step-up infusion $(\bullet-\bullet)$ and poor control/basal infusion $(\longleftrightarrow \mathbf{\wedge})$. Bars denote mean $\pm \mathrm{SEM}$

$12.6 \pm 0.8 \mathrm{mmol} / \mathrm{l}$ at $14 \mathrm{~h}$. When the insulin infusion rate was incrementally increased after the meal, the glucose concentration rose to a peak of $8.8 \pm 0.6 \mathrm{mmol} / \mathrm{l}$ at $1 \mathrm{~h}$ and then stabilized between 5 and $6 \mathrm{mmol} / 1$ from $6 \mathrm{~h}$ onwards. In the poor control/basal infusion study the postprandial increase in glucose was greater, reaching a maximum of $23.0 \pm 0.5 \mathrm{mmol} / \mathrm{l}$ at $4 \mathrm{~h}$ and then slowly declining to $12.5 \pm 0.6 \mathrm{mmol} / \mathrm{l}$ at $14 \mathrm{~h}$. Control subjects demonstrated very little postprandial increment in glucose concentration as demonstrated in Figure 1.

Insulin levels at the start of the meal were similar for all three protocols in the diabetic patients but these levels were significantly higher than those in the control subjects only in the good control/step-up infusion protocol
G. F. Lewis et al.: Postprandial lipoprotein metabolism in Type 1 diabetes

$(78.0 \pm 6.8 \mathrm{pmol} / 1$ vs $37.7 \pm 5.2 \mathrm{pmol} / 1, p<0.001)$. In the good control/basal infusion and poor control/basal infusion studies, insulin concentrations did not change significantly during the $24 \mathrm{~h}$ postprandial period, the mean insulin level being $44.7 \pm 1.8 \mathrm{pmol} / 1$ and $49.0 \pm 2.3 \mathrm{pmol} / \mathrm{l}$, respectively. In the good control/step-up infusion proto$\mathrm{col}$, the peak insulin was $360.0 \pm 69.6 \mathrm{pmol} / 1$ at $3 \mathrm{~h}$, a 3.9 fold increase over baseline. Peak insulin level in control subjects was $166.2 \pm 43.1 \mathrm{pmol} / \mathrm{l}$ at $1 \mathrm{~h}$, a 4 .4-fold increase over baseline.

C-peptide remained suppressed in all diabetic patients after the meal, confirming an absolute deficiency of endogenous insulin production in these patients. The mean C-peptide concentration in the control subjects before the meal was $0.34 \pm 0.06 \mathrm{nmol} / \mathrm{l}$. The $C$-peptide levels increased following the meal, reaching a maximum of $1.13 \pm 0.21 \mathrm{nmol} / 1$ at $2 \mathrm{~h}$.

\section{Postprandial triglycerides, $H D L$-cholesterol} and total cholesterol levels

Plasma triglyceride concentrations rose to a maximum at 3 to $5 \mathrm{~h}$ following the test meal in all groups (Fig. 2). There were no differences in triglyceride increment, peak triglyceride response or timing of peak response between the three insulin protocols in the diabetic patients or between diabetic and control subjects.

HDL-cholesterol (Fig. 2) decreased significantly from baseline in all three diabetic protocols and also in the control subjects at 3 to $5 \mathrm{~h}(p<0.0005)$. HDL-cholesterol then rose initially towards baseline in all protocols and there was a later overall lowering of HDL-cholesterol in the three diabetic protocols but not in the control subjects. However, none of these changes in HDL cholesterol concentrations after the first $5 \mathrm{~h}$ were statistically significant. HDL-cholesterol tended to be highest at all times in the diabetic poor control/basal infusion study but this was of borderline significance $(p<0.05)$.

Total cholesterol tended to decrease overall with time after the meal but there was extreme individual variability within each group and overall no clearly significant trends were detected.

\section{Postprandial non-esterified fatty acids (NEFA) (Fig. 2)}

In both the good control/basal infusion and the poor control/basal infusion protocols, the NEFA concentrations rose within $1 \mathrm{~h}$ following the test meal with a peak at about $3 \mathrm{~h}$. The areas under the respective curves for these two studies were $23.74 \pm 1.35 \mathrm{mmol} \cdot 1^{-1} \cdot 24 \mathrm{~h}^{-1}$ and $24.23 \pm$ $1.31 \mathrm{mmol} \cdot 1^{-1} \cdot 24 \mathrm{~h}^{-1}$ and were greater than for the good control/step-up infusion protocol $(16.03 \pm 1.58 \mathrm{mmol}$ $\left.\mathrm{l}^{-1} .24 \mathrm{~h}^{-1}, p<0.0005\right)$ and the control subjects $(18.51 \pm$ $\left.0.87 \mathrm{mmol} \cdot 1^{-1} \cdot 24 \mathrm{~h}^{-1}, p<0.01\right)$. In the latter two studies, there was an early decrease in NEFA before returning towards baseline levels. In the good control/step-up infusion protocol, NEFA decreased from $0.677 \pm 0.127 \mathrm{mmol} / 1$ at zero time to $0.433 \pm 0.057 \mathrm{mmol} / \mathrm{l}$ at $2.9 \mathrm{~h}(p<0.05)$ and 


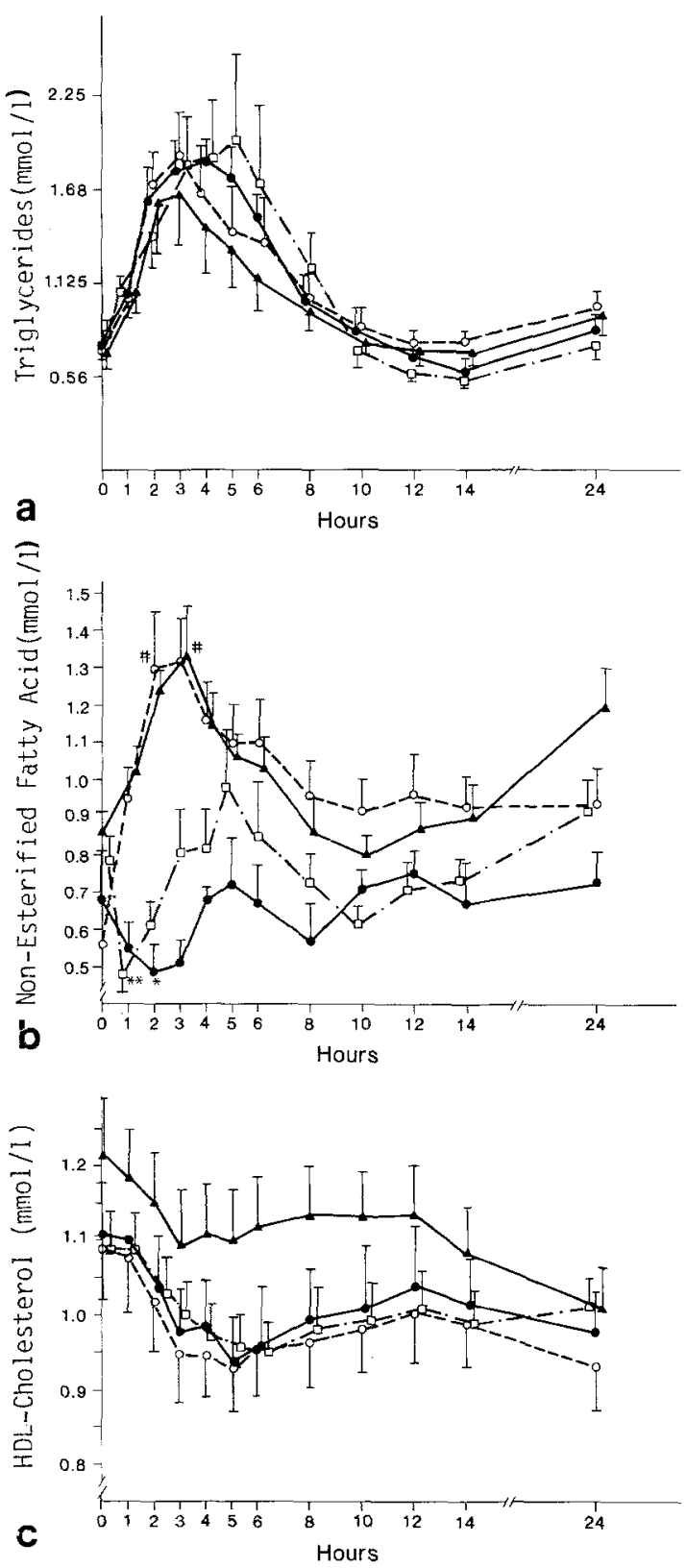

Fig. 2. Triglyceride, HDL-cholesterol and non-esterified fatty acid concentrations at baseline (zero hour) and for $24 \mathrm{~h}$ following ingestion of the test meal for control subjects $(\square---\square)$ and diabetic patients studied in the three protocols: Good control/basal infusion $(0-\cdots)$, good control/step-up infusion $(-)$ ) and poor control/basal infusion (\lrcorner $\mathbf{A})$. Bars denote mean \pm SEM. Statistics for decrease from zero time. $* p<0.05$; ** $p<0.005$. Statistics for differences from controls for area under the respective curves. \# $p<0.01$

in the control subjects, NEFA decreased from $0.791 \pm$ $0.063 \mathrm{mmol} / \mathrm{l}$ to $0.478 \pm 0.045 \mathrm{mmol} / \mathrm{l}$ at $1.1 \mathrm{~h}(p<0.005)$.

\section{Retinyl palmitate (RP) (Fig.3)}

There were no significant differences in RP increment, peak RP response or timing of peak response when measured in whole plasma, chylomicron fraction $\left(S_{\mathrm{f}}>1000\right)$ or non-chylomicron fraction $\left(S_{\mathrm{f}}<1000\right)$ be-
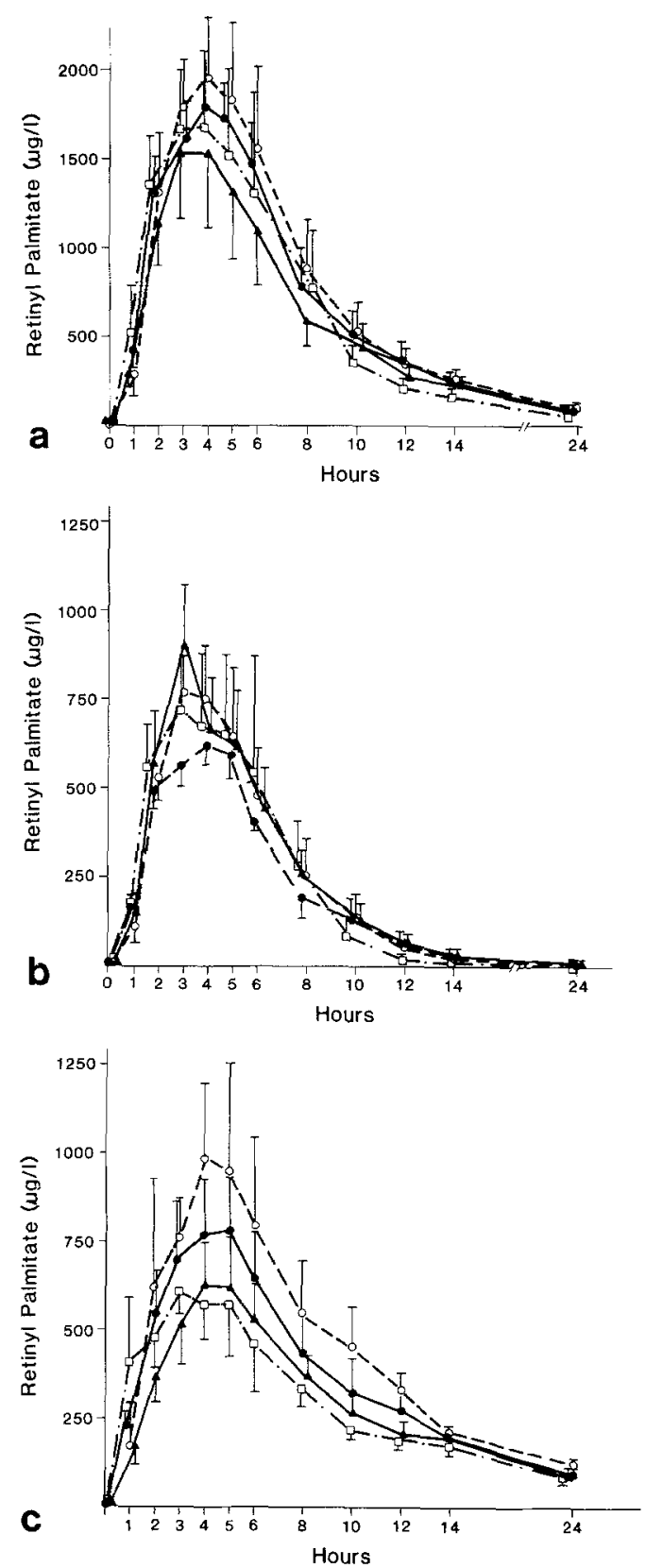

Fig.3. Retinyl palmitate (RP) measured in whole plasma (top panel), chylomicron fraction $S_{f}>1000$ ) (centre panel) and nonchylomicron fraction $\left(S_{\mathrm{f}}<1000\right)$ (lower panel) for control subjects $(\square--\square)$ and diabetic patients studied in the three protocols: Good control/basal infusion $(\mathrm{O}-\cdots)$, good control/step-up infusion $(\bullet-\bullet)$, and poor control/basal infusion (\lrcorner $\mathbf{\Lambda})$. Bars denote mean \pm SEM

tween the three diabetic protocols or between diabetic and control subjects.

\section{Significant correlations (Table 2)}

Fasting triglyceride concentration correlated significantly with the area under the chylomicron RP curve in all three diabetic protocols as well as with the postprandial incremental area under the triglyceride curve in the good 
Table 2. Correlation coefficients between fasting triglyceride concentrations and areas under the postprandial triglyceride and chylomicron response curves

\begin{tabular}{|c|c|c|c|c|}
\hline & $\begin{array}{l}\text { Type } 1 \text { diabetic subjects } \\
\text { Good control/ } \\
\text { basal infusion }\end{array}$ & $\begin{array}{l}\text { Type } 1 \text { diabetic subjects } \\
\text { Good control/ } \\
\text { step-up infusion }\end{array}$ & $\begin{array}{l}\text { Type } 1 \text { diabetic subjects } \\
\text { Poor control/ } \\
\text { basal infusion }\end{array}$ & $\begin{array}{l}\text { Control } \\
\text { subjects }\end{array}$ \\
\hline $\begin{array}{l}\text { Incremental triglyceride area } \\
\left(\mathrm{mmol} \cdot \mathrm{I}^{-1} \cdot 24 \mathrm{~h}^{-1}\right)\end{array}$ & $\begin{array}{l}r=0.72 \\
p=0.07\end{array}$ & $\begin{array}{l}r=0.79 \\
p<0.05\end{array}$ & $\begin{array}{l}r=0.30 \\
p=0.51\end{array}$ & $\begin{array}{l}r=0.60 \\
p=0.16\end{array}$ \\
\hline $\begin{array}{l}\text { Chylomicron RP area } \\
\left(\mu \mathrm{g} \cdot 1^{-1} \cdot 24 \mathrm{~h}^{-1}\right)\end{array}$ & $\begin{array}{l}\dot{r}=0.87 \\
p=0.01\end{array}$ & $\begin{array}{l}r=0.78 \\
p<0.05\end{array}$ & $\begin{array}{l}r=0.88 \\
p<0.01\end{array}$ & $\begin{array}{l}r=0.68 \\
p=0.10\end{array}$ \\
\hline
\end{tabular}

Abbreviations: RP = Retinyl palmitate

control/step-up infusion and the good control/basal infusion protocols. There were no significant correlations between fasting triglycerides and area under either the whole plasma RP or non-chylomicron RP curves.

\section{Discussion}

The present study was designed to examine the effects of short-term alterations in glycaemic control and peri-meal insulin replacement on postprandial lipoprotein metabolism in Type 1 diabetes. While a number of previous studies have examined the effects of improvement in diabetic control on lipoprotein metabolism both in the fasting and postprandial periods [5-9], this is to our knowledge the first study of postprandial triglyceride and lipoprotein metabolism in Type 1 diabetes following deliberate attempts to worsen the level of glucose control. We found that two weeks of moderate deterioration in glycaemic control (no ketosis) did not alter either fasting or postprandial lipids and moreover that following an overnight euglycaemic insulin infusion, the level of insulin replacement at the time of the meal did not influence the metabolism of ingested fat. Non-esterified fatty acids (NEFA), on the other hand were significantly affected by acute variations in insulin levels and therefore appear to be a far more sensitive index of insulinization than triglycerides.

The negative findings in this study were unexpected in view of the experimental evidence demonstrating that short-term improvement in glycaemic control over a two to three week period in chronically poorly-controlled Type 1 patients results in a decrease in fasting triglycerides. Kinetic studies have demonstrated that such decreases are due to reduced hepatic VLDL triglyceride synthesis rates rather than to increased clearance rates $[8$, 26]. While deteriorating glycaemic control for periods as short as three weeks might therefore be expected to lead to an increase in VLDL triglyceride synthesis and a subsequent increase in serum triglyceride levels, the latter was not observed in our study. Although the reason for this discrepancy is not immediately apparent, it is conceivable that the rate limiting step responsible for suppressing VLDL synthesis during periods of good control may be different from the rate limiting step regulating enhanced VLDL production as the level of diabetic control deteriorates. During periods of good glycaemic control, the abrupt fall in triglyceride levels which has been reported may be a reflection of a rapid inhibition of lipolysis leading to an immediate reduction in the amount of substrate available for VLDL triglyceride synthesis, whereas during periods of poor control, the hepatic response to the increased availability of substrate may take some time to manifest. Whatever the mechanism, since fasting triglyceride levels in both diabetic and control subjects were similar in this study and since the incremental triglyceride response to a meal in diabetic and in non-diabetic patients is critically dependent on the basal triglyceride concentration $[9,14]$, it is not surprising that the postprandial triglyceride and RP responses in both groups were similar.

Although lipoprotein lipase activity has been shown to increase in response to insulin and glucose stimuli [27-29], there was no observed difference in postprandial chylomicron clearance following the overnight euglycaemic insulin infusion when insulin was either held constant at a low basal rate or increased after the meal. It thus seems likely that the peripheral hyperinsulinaemia induced by the overnight insulin infusion was sufficient to result in maximum stimulation of lipoprotein lipase activity and further increases in postprandial insulin levels were unable to stimulate lipolytic activity further.

NEFA concentrations rose significantly after the meal when the insulin infusion rate was held constant at $0.4 \mathrm{U} / \mathrm{h}$ but did not increase when the insulin infusion was increased four-fold after the meal to simulate the physiological increase in insulin secretion rate which occurs postprandially. Chylomicron triglycerides are hydrolysed to NEFA prior to their entrance into adipose tissue cells [30] and the key factors affecting deposition in the cells are the rate of hydrolysis by lipoprotein lipase and rate of re-esterification of NEFA in the tissue [31]. Since the NEFA rise in patients with low basal insulin levels occurred acutely at the time of the meal, it is most likely that the NEFA's originate from lipolysis of enterically-derived triglycerides packaged within chylomicrons and this rise is inversely related to the degree of effective insulinization at the time of the meal. In support of this latter observation, we have previously demonstrated an early decrease in NEFA levels at 1 to $3 \mathrm{~h}$ after the meal in association with a rapid rise in insulin levels in a group of non-diabetic obese subjects [14]. This phenomenon is demonstrated again in the present study, not only in the control subjects but also in the Type 1 diabetic patients when insulin was incrementally increased at the start of the meal.

We conclude that in normotriglyceridaemic Type 1 diabetic patients, short-term deterioration in glucose control resulting from reduction in insulin dose does not alter 
basal and postprandial lipoprotein concentrations. On the other hand, NEFA disposal in the postprandial state appears to be far more sensitive to effective ambient insulin levels at the time of the meal.

Acknowledgements. We would like to thank Dr. T. Karrison for his assistance with the statistical computations, Ms. B. Brogan for her expert secretarial help and the staff of the Clinical Research Centre at the University of Chicago for their support. This work was supported by NIH Grants DK-31842, DK-13941, DK-20595 (Diabetes Research and Training Centre), HL 15062-18 (SCOR in Atherosclerosis), DK-26678 (Clinical Nutrition Research Unit), RR-00055 (The Clinical Research Centre) and a Research Grant from the Juvenile Diabetes Foundation (188414). Dr. Lewis is supported by funding from the PEW National Nutrition Programe.

\section{References}

1. Sosenko JM, Breslow JL, Miettinen OS, Gabbay KH (1980) Hyperglycemia and plasma lipid levels. A prospective study of young insulin-dependent diabetic patients. $\mathrm{N}$ Engl J Med 302: $650-654$

2. Lopes-Virella MF, Wohltmann HJ, Loadholt CB, Buse MG (1981) Plasma lipids and lipoproteins in young insulin-dependent diabetic patients: relationship with control. Diabetologia 21:216-223

3. Nikkila EA, Hormila P (1978) Serum lipids and lipoproteins in insulin-treated diabetes. Demonstration of increased high density lipoprotein concentrations. Diabetes 27: 1078-1086

4. Gonen B, White N, Schonfeld G, Skor D, Miller P, Santiago J (1985) Plasma levels of apoprotein B in patients with diabetes mellitus: the effect of glycemic control. Metabolism 34: 675-679

5. Pietri A, Dunn FL, Raskin P (1980) The effect of improved diabetic control on plasma lipid and lipoprotein levels. A comparison of conventional therapy and continuous subcutaneous insulin infusion. Diabetes 29: 1001-1005

6. Tamborlane WV, Sherwin RS, Genel M, Felig P (1979) Restoration of normal lipid and amino acid metabolism in diabetic patients treated with a portable insulin-infusion pump. Lancet I: 1258-1261

7. Hershcopf R, Plotnick LP, Kaya K, Benedict GW, Hadji-Georgopoulos A, Margolis \$, Kowarski AA (1982) Short term improvement in glycemic control utilizing continuous subcutaneous insulin infusion: the effect on 24-hour integrated concentrations of counterregulatory hormones and plasma lipids in insulin-dependent diabetes mellitus. J Clin Endocrinol Metab 54: 504-509

8. Pietri AO, Dunn FL, Grundy SM, Raskin P (1983) The effect of continuous subcutaneous insulin infusion on very-low-density lipoprotein triglyceride metabolism in Type 1 diabetes mellitus. Diabetes 32: 75-81

9. Georgopoulos A, Margolis S, Backorik P, Kwiterowich PO (1988) Effect of improved glycemic control on the response of plasma triglycerides to ingestion of a saturated fat load in normotriglyceridemic and hypertriglyceridemic diabetic subjects. Metabolism 37: 866-871

10. Streja DA, Marliss EB, Steiner G (1977) The effects of prolonged fasting on plasma triglyceride kinetics in man. Metabolism 26: 505-516

11. Taskinen M-R (1987) Lipoprotein lipase in diabetes. Diabetes Metab Rev 3: $551-570$ (Review)

12. The Lipid Research Clinics Population Studies Data Book (1980) Vol 1. The Prevalence Study. Lipid Metabolism Branch, Division of Heart and Vascular Diseases, National Heart, Lung and Blood Institute. US Department of Health and Human Services, Public Health Science, National Institutes of Health. NIH publication no. 80-1527. Government Printing Office

13. White NH, Skor D, Santiago JV (1982) Practical closed-loop insulin delivery. A system for the maintenance of overnight eu- glycemia and the circulation of basal insulin requirements in insulin-dependent diabetics. Ann Intern Med 97:210-213

14. Lewis GF, O'Meara NM, Soltys PA et al. (1990) Postprandial lipoprotein metabolism in normal and obese subjects. Comparison after the Vitamin A fat loading test. J Clin Endocrinol Metab 71: 1041-1050

15. Weintraub MS, Eisenberg S, Breslow JL (1987) Different patterns of postprandial lipoprotein metabolism in normal, Type IIa, Type III and Type IV hyperlipoproteinemic individuals. Effects of treatment with cholestyramine and gemfibrozil. J Clin Invest 79: 1110-1119

16. Olson JA (1969) Metabolism and function of Vitamin A. Fed Proc 28: 1670-1677

17. Goodman DS, Blomstrand R, Wenner G, Huang HS, Shiratori T (1966) The intestinal absorption and metabolism of Vitamin A and beta carotene in man. J Clin Invest 45: 1615-1623

18. Thompson KH, Hughes LB, Zilversmit DB (1983) Lack of secretion of retinyl esters by livers of normal and cholesterol-fed rabbits. J Nutr 113: 1995-2001

19. Berr F, Kern F Jr (1984) Plasma clearance of chylomicrons labeled with retinyl palmitate in healthy human subjects. J Lipid Res 25: 805-812

20. Grundy SM, Mok HYI (1976) Chylomicron clearance in normal and hyperlipidemic man. Metabolism 25: 1225-1239

21. Mikac-Devic D, Stankovic H, Boskovic K (1983) A method for determination of free fatty acids in serum. Clin Chim Acta 45 : $55-59$

22. Lowry OH, Rosebrough NJ, Farr AL, Randall RJ (1951) Protein measurement with the folin phenol reagent. J Biol Chem 193: 265-275

23. Ruyter MGM de, Leenheer AP de (1978) Simultaneous determination of retinol and retinyl esters in serum or plasma by reversed-phase high-performance liquid chromatography. Clin Chem 24: 1920-1923

24. Morgan CR, Lazarow A (1963) Immunoassay of insulin: two antibody system. Plasma insulin levels of normal, subdiabetic and diabetic rats. Diabetes 12:115-126

25. Faber OK, Binder C, Markussen J et al. (1978) Characterization of seven C-peptide antisera. Diabetes 27 [Suppl 1]: 170-177

26. Dunn FL, Carroll PB, Beltz WF (1987) Treatment with artificial $\beta$-cell decreases very-low-density lipoprotein triglyceride synthesis in Type 1 diabetes. Diabetes 36: 661-666

27. Nilsson-Ehle P, Carlstrom S, Belfrage P (1975) Rapid effects of lipoprotein lipase activity in adipose tissue of humans after carbohydrate and lipid intake. Time course and relation to plasma glycerol, triglyceride and insulin levels. Scand J Clin Lab Invest 35: $373-378$

28. Sadur GN, Eckel RH (1982) Insulin stimulation of adipose tissue lipoprotein lipase. Use of the euglycemic clamp technique. I Clin Invest 69: 1119-1125

29. Yki-Jarvinen H, Taskinen M-R, Koivisto VA, Nikkila EA (1984) Response of adipose tissue lipoprotein lipase activity and serum lipoproteins to acute hyperinsulinaemia in man. Diabetologia 27: 364-369

30. Havel RJ, Goldfien A (1961) The role of the liver and of extrahepatic tissues in the transport and metabolism of fatty acids and triglycerides in the dog. J Lipid Res 2: 389-395

31. Havel RJ, Felts JM, Duyne CM van (1963) Formation and fate of endogenous triglycerides in blood plasma of rabbits. J Lipid Res $3: 297-308$

Received: 7 June 1990

and in revised form: 6 November 1990

Dr.K.S.Polonsky

University of Chicago

Department of Medicine

Box 435

5841 South Maryland Avenue

Chicago, IL 60637

USA 